\title{
Adaptation of Spiritual Transcendence Scale to Turkish: Validity and Reliability Study
}

\author{
Yakup IME, Milli Eğitim Bakanlığı, ORCID:0000-0001-6818-8044 \\ Halil EKŞi, Marmara Üniversitesi, ORCID:0000-0001-7520-4559 \\ Füsun EKŞi, Medeniyet Üniversitesi; ORCID:0000-0001-5741-2725
}

\begin{abstract}
The purpose of this study was to adapt Spiritual Transcendence Scale developed by Piedmont (1999) into Turkish and to examine its reliability and validity. Data was collected from three different study groups involving a total of 534 university students of which 277 were female and 257 male. The psychometric properties of the scale were examined by confirmatory factor analysis, criterion related validity and internal consistency. The results of confirmatory factor analysis demonstrated that three factor structure of the Spiritual Transcendental Scale has been validated. In the context of the criterion related validity, positive correlations were found between Spiritual Transcendence Scale and Spiritual Orientation Scale. The Cronbach's alpha for the total scale was .90. It is concluded that the Spiritual Transcendence Scale is valid and reliable instrument to measure spiritual transcendence level
\end{abstract}

Keywords: spiritual transcendence, scale adaptation, validity, reliability
İnönü University

Journal of the Faculty of Education Vol 20, No 3, 2019

pp. $1008-1020$

DOI: $10.17679 /$ inuefd. 562410

Article type:

Research article 


\section{EXTENDED ABSTRACT}

\section{Introduction}

Turkey is located in a geographical area with a rich spiritual heritage. Despite such richness, it is observed in literature reviews that the perception of spirituality is not studied sufficiently in psychotherapy and psychological counseling. Shafranske and Gorsuch (1984) defines spirituality as a transcendent dimension in human experience in which the individual questions the meaning of personal existence and attempts to place the self within a broader ontological context. Doyle (1992), on the other hand, defines spirituality as an existential search for meaning. This search for meaning has, in fact, been a part of human experience from the beginning of humankind. Although there was a lack of studies on the perceptions related with spirituality in the $20^{\text {th }}$ century (Hill, Pargament, Hood, McCullough, Swyers, Larson and Zinnbauer, 2000), psychologists have begun to show more interest in perceptions associated with religion and spirituality in the $21^{\text {st }}$ century (Zinnbauer and Pargament,2005). As a result of this increased interest, measurement tools for assessing spirituality-related perceptions from various aspects have started to be developed in our country and around the world (Delaney, 2005;Kasapoğlu, 2015; Ekşi, Okan, Kömürcü,2018).

Piedmont (1999) expresses that spirituality can be perceived as a universal human experience and has developed the Spiritual Transcendence Scale after asking for the opinions of scientists from different religious groups. Through spiritual transcendence, an individual can adapt to life with a broader and integral perspective and create a bond between oneself and humankind.

\section{Purpose}

It is observed that various measurement tools for the assessment of spiritual characteristics have been developed in our country in recent years (Kasapoğlu, 2015; Şirin 2018). However, it is seen that there is not a measurement tool among the available scales to assess the spiritual transcendence. Therefore, the objective of this study is to adapt the spiritual transcendence scale developed by Piedmont into the Turkish language and examine the psychometric features of this scale. It is considered that this study will be useful for practitioners and researchers working in the field of mental health in Turkey.

\section{Method}

Data was collected from three different groups in the present study. Firstly, a total of 42 students comprising 22 women and 20 men (52.4\%women,47.6\% men) and studying in philosophy, psychology and English language and literature departments at a university, where the courses are in English, during the fall term of 2018-2019 academic year participated in the study for linguistic validity test. 424 students consisting of 217 women and 207 men (51.2\%women, 48.8\% men) and studying in Marmara University also participated in the study for confirmatory factor analysis conducted to determine the construct validity of the scale and reliability test. Finally, for the criterion-referenced validity test, a total of 68 students - 38 women and 30 men (55.9\%women, 44.1\% men)- studying in Health Sciences Vocational School of Istanbul Gelisim University were included in the study. Confirmatory factor analyzes were performed to determine the construct validity of the scale. The cronbach Alpha coefficient was calculated for the internal consistency reliability of the scale. In order to determine the criterion validity of the scale, the correlation between Spiritual Orientation Scale developed by Kasapoğlu (2015) was examined.

\section{Findings}

The correlation coefficient between the scores from the English questionnaire and the Turkish questionnaire was calculated as $r=.94(p<.01)$. In terms of subscales, the correlation coefficient between the English questionnaire and Turkish questionnaire was found as $r=.91$ for the prayer fulfillment subscale, $r=$. 91 for the universality subscale and $r=.85$ for the connectedness subscale. Based on the results, it can be concluded that the scale's Turkish version is equivalent to the original English version.

According to the results of dependent samples t-test conducted to determine the equivalence of the Turkish version of Spiritual Transcendence Scale to the original English version, no significant difference was detected between them $(p>.05)$. In t-test analysis performed for linguistic equivalence, no problems were present in the items and correlation values were statistically significant. Thus, it can be said that all 
scale items have linguistic validity. Based on all of these results, it was detected that the Turkish version of the scale was equivalent to the English version.

The method of confirmatory factor analysis was used to determine whether the Spiritual Transcendence Scale was confirmed in the sample consisting of university students in Turkey. CFA results were firstly assessed based on the ratio of chi-square value to the degree of freedom. The ratio of chi-square value to the degree of freedom must be below 5 (Kline, 2005). In the present study, this ratio (681.09/249) was calculated as 2.73. For the model's goodness of fit indices, it is reported that the acceptable fit index value is .90 and above for TLI, CFI, GFI and IFI and .08 and below for RMSEA and SRMR (Tabachnick and Fidell, 2001). It was detected in line with these criteria that the model exhibited a good fit.

The factor loads of the scale range from .31 to .97 . The model's fit indices demonstrate that the threedimensional model of the scale indicated an acceptable fit. A positive correlation (.66) was found between the total score from the Spiritual Transcendence Scale and the total score from the Spiritual Orientation Scale (.66). A positive correlation was also detected between the spiritual orientation scale and the prayer fulfillment (0.79), universality (0.38) and connectedness (.36) subscales of the spiritual transcendence scale. Obtained values can be evaluated as evidence of the validity of Spiritual Transcendence Scale. Cronbach Alfa internal consistency reliability coefficient was calculated as .90 for the entire Spiritual Transcendence Scale. For the subscales, internal consistency reliability coefficient was found as .84 for the prayer fulfilment, .91 for universality and .93 for connectedness.

\section{Discussion \& Conclusion}

The results of validity studies conducted for the spiritual transcendence scale indicate that it is a valid measurement tool. In the confirmatory factor analysis, it is observed that the 3 subscales in the original version are confirmed. The correlation values obtained as a result of the confirmatory factor analysis range from 31 to 97 . It is stated that the items with a value of .30 and above are represented adequately (Büyüköztürk, 2004). Thus, none of the items was removed from the original version during the scale's adaptation to Turkish. It was detected that the fit index values of the scale were acceptable and its 3dimensional structure was valid in this study group. Results can be used as evidence that the spiritual transcendence scale is a valid measurement tool.

Following the development of the spiritual transcendence scale (Piedmont, 1999), the adaptation studies conducted in India (Piedmont and Leach,2002) and the Philippines (Piedmont, 2007) support the fact that the scale is a valid and reliable measurement tool in different cultures. The present study reveals that the scale produces psychometrically valid and reliable results in Turkey as well, which can be explained with the universality of spirituality. 


\title{
Manevi Aşkınlık Ölçeği'nin Türkçeye Uyarlanmast: Geçerlik ve Güvenirlik Çalışması
}

\author{
Yakup iME, Milli Eğitim Bakanlığı, ORCID:0000-0001-6818-8044 \\ Halil EKŞi, Marmara Üniversitesi, ORCID:0000-0001-7520-4559 \\ Füsun EKŞi, Medeniyet Üniversitesi; ORCID:0000-0001-5741-2725
}

Öz

Bu çalışmanın amacı Piedmont (1999) tarafından geliştirilen Manevi Aşkınlık Ölçeği'ni Türkçeye uyarlayarak geçerlik ve güvenirlik çalışmalarını gerçekleştirmektir. Araştırmaya üç farklı katılıma grubundan oluşan 277 kadın ve 257 erkek olmak üzere toplam 534 üniversite öğrencisi katılmıştır. Ölçeğin psikometrik özellikleri; iç tutarlık, dil geçerlik, ölçüt bağlantı geçerlik ve doğrulayıcı faktör analizi yöntemleri ile incelenmiştir. Ölçeğin yapı geçerliği için doğrulayıcı faktör analizi yapılmış ve manevi aşkınlık ölçeğinin alt boyutlarını oluşturan üçlü yapı doğrulanmıştır. Ölçüt bağlantı geçerlik çalışması sonucunda manevi aşkınlık ölçeği ile manevi yönelim ölçeği arasında pozitif yönlü anlamlı ilişkiler bulunmuştur. İ̧ tutarlık güvenirlik Cronbach alpha katsayısının ölçeğin geneli için. 90, alt boyutları ibadet doyumu için .84, evrensellik için .91 ve bağlantılılık için .93 olarak hesaplanmıştır. Araştırma sonuçları Manevi Aşkınlık Ölçeği Türkçe formunun geçerli ve güvenilir bir ölçme aracı olduğunu ve Türkiye'de yürütülecek bilimsel çalıșmalarda kullanılabileceğini ortaya koymuştur.

Anahtar Kelimeler:manevi aşkınlık, ölçek uyarlama, geçerlik, güvenirlik.

.

\section{İnönü Üniversitesi}

Eğitim Fakültesi Dergisi

Cilt 20, Sayı 3, 2019

ss. $1008-1020$

DOI: $10.17679 /$ inuefd. 562410

Makaletürü:

Araştırmamakalesi

Gönderim Tarihi : 09.05.2019

Kabul Tarihi : 05.01.2020

\section{Önerilen Atıf}

İme,Y., Ekşi, H., Ekşi, F. (2019).Manevi aşkınlık ölçeğinin Türkçe'ye uyarlanması: geçerlik ve güvenirlik çalışması. Inönü Üniversitesi Eğitim Fakültesi Dergisi, 20(3), 1008-1020. DOI: 10.17679/inuefd.562410 


\section{GíRiş}

Ülkemiz zengin manevi birikime sahip bir coğrafyada yer almaktadır. Bu zenginliğe rağmen alanyazın incelendiğinde psikoterapi ve psikolojik danışmanlık alanlarında maneviyat kavramının yeterli düzeyde çalışılmadığı görülmektedir. Maneviyat, Shafranske ve Gorsuch (1984) tarafından bireyin varoluşunun anlamını sorguladığı, varoluşunu ontolojik olarak daha geniş bir bağlamda ele almaya çalışı̆̆ı yaşantısında aşkın bir boyut olarak tanımlanmaktadır. Doyle (1992) ise maneviyatı varoluşsal anlam arayışı olarak ifade etmektedir. Bu anlam arayışı esasen insanlık var olduğu sürece insan yaşantısının bir parçası olmuştur. 20. yüzyılda maneviyatla ilgili kavramlarda yapılan araştırmalarda durgunluğa rağmen (Hill, Pargament, Hood, McCullough, Swyers, Larson ve Zinnbauer, 2000) 21. yüzyılda psikologlar din ve maneviyat ile ilgili kavramlara daha fazla ilgi göstermeye başlamıştır (Zinnbauer ve Pargament,2005).Bu artan ilgi ile birlikte maneviyatla ilgili kavramları çeşitli açılardan değerlendirmeye yönelik ölçüm araçları dünyada ve ülkemizde geliştirilmeye başlanmıştır (Delaney, 2005;Kasapoğlu, 2015; Ekşi, Okan,Kömürcü,2018). Piedmont (1999) ise maneviyatın tüm insanlık için evrensel olabileceğini belirterek farklı dini gruplarından bilim insanlarının da görüşlerine başvurarak Manevi Aşkınlık Ölçeği'ni geliştirmiştir.

Piedmont (2001) maneviyatı bireyin geniş bir anlam duygusu oluşturma çabaları olarak ifade etmektedir.

Aşkınlık normal bir farkındalık eşiğinin üstünde olduğu gibi, bireyin sıradanları aşıp, belirli bir farkındalık seviyesinin ötesine geçip, ileri düzey bir farkındalığa erişmesini ifade eder (Oxford Dictionary, 2017).Manevi aşkınlık ise Piedmont'a (1999) göre bireyin bulunduğu zaman ve mekanın dışına çıkarak, dünyayı daha geniş ve objektif bir bakış açııından görebilme kapasitesi olarak tanımlanır. Aşkınlık bireyin davranışlarını yöneten içsel bir motivasyon kaynağıdır. Manevi aşkınlıkla birey,daha geniş ve bütüncül perspektifte hayatla uyumu yakalar ve insanlıkla arasında bir bağ kurar.Seidlitz,Abernethy, Duberstein, Evinger, Chang ve Lewis (2002) ise manevi aşkınlığı kişinin kendi algııını, duygularını, hedeflerini ve karşılaştığı zorlukları aşma yeteneğini etkileyen kutsalın öznel deneyimi olarak ifade etmektedir.

Manevi aşkınlık dindarlıktan farklıdır ve daha geniş bir alanı kapsar. Manevi aşkınlık büyük bir kutsallıkla bağlantılı olmak için kişisel arayışı ifade ederken, dindarlık illahi olanla yüzleşmek ve karşılaşmak için sosyal vurguyu sağlamayı belirtir. Manevi aşkınlığın bileşenlerinden bir tanesi bağlantılılık hem dikey (kuşaklar arası bağlılık) hem de yatay (toplumumdaki diğer kişilere olan bağlıık) olarak diğerlerine karşı kişisel sorumluluk duygusunu belirtir. Evrensellik ise yaşamın birliği ve amacına dair bir inançtır; tüm yaşamların birbirine bağlı olduğu ve bir varlığın diğerine karşı hissettiği ortak sorumluluk hissini belirtir. İbadet doyumu ise yapılan ibadetten kaynaklanan bir sevinç ve gönül ferahlığı hissidir. İbadet doyumu kişiye kişisel bir güç hissi sağlar ve kişiyi başka bir varoluş evresine yönlendirir (Piedmont, 1999).

Maneviyatla ilgili konulara olan ilgi ülkemizde de görülmeye başlanmakta olup bu kavrama ilişkin çalışmalar son zamanlarda yapılmaktadır (Ekşi, Takmaz ve Kardaş, 2016;Şirin,2018; İme, 2019).Maneviyat danışanın problem algılamasında ev anlamlandırmasında dinamik bir etkiye sahiptir. Terapötik ilişkide danışanın manevi ilgilerini belirleyebilmek amacıyla danışanın dini ve manevi ilgilerini anlamak önem taşır (Bray,2011). Bu sebeple ülkemizde de danışanın manevi ilgilerinin belirleyip değerlendirebilecek ölçme araçları ihtiyacı oluşacağı düşünülmektedir. Bu bağlamda maneviyat ve ilgili kavramların değerlendirilmesine yönelik ölçüm araçlarının geliştirilmesi ve uyarlanması önem arz etmektedir.

Manevi aşkınlık ölçeği daha önce yapılan çalışmalarla Hindistan'da (Piedmont ve Leach,2012) Müslüman ve diğer dini grup mensuplarının katılımcı olarak yer aldığı uyarlama çalışması yapılmışıı. Ayrıca Filipinlerde (Piedmont,2007)uyarlama çalışmaları yapılmıştır. Farklı kültürlere uyarlanan Manevi Aşkınlık Ölçeği'nin psikometrik özellikleri geçerli ve güvenilir bir ölçme aracı olduğunu göstermektedir. Ülkemizde son yıllarda manevi özelliklerinin ölçülebilmesine yönelik çeşitli ölçüm araçlarının geliştirildiği görülmektedir (Kasapoğlu, 2015; Şirin 2018). Ancak mevcut ölçekler incelendiğinde manevi aşkınlığı değerlendirmeye yönelik bir ölçme aracının olmadığı görülmektedir. Dolayısıyla, bu çalışmanın amacı Piedmont tarafından geliştirilen manevi aşkınlık ölçeğinin Türkçeye uyarlamak ve bu ölçeğin psikometrik özelliklerini incelemektir. Yapılacak olan bu çalışmanın Türkiye'deki ruh sağığı alanında çalışan uygulayıcı ve araştırmacılar için faydalı olacağı düşünülmektedir.

\section{Manevi Aşkınlık Ölçeğinin Geliştirilmesi}

Manevi aşkınlık ölçeğinin geliştirilmesinde Budizm, Hinduizm, Katoliklik ve Yahudilik dahil olmak üzere çeşitlik inanç geleneklerinden farklı teolojik uzmanlar bir araya gelmişlerdir. Bu çalışma grubu tüm inançlar için ortak olan maneviyatın boyutlarını tanımlamışlardır. Manevi Aşkınlık Ölçeği'nin geliştirme çalışmasına 
ABD'de bulunan Midwestern Üniversitesi'nde öğrenim gören yaşları 17 ile 40 arası değişen toplam 381 kişi katılmıştır. Doğrulama çalışmasına ise yine aynı üniversiteden yaşları 17 ile 52 arasında değişen toplam 356 kişi katılmıştır. Manevi Aşkınlık Ölçeği'nin geliştirilmesi aşamasında ilk olarak 65 maddeden oluşan bir madde havuzu oluşturulmuştur. Daha sonra yapılan analizlerle birlikte faktör yükleri .30'un altında olan maddeler çıkarılmış ve ölçeğin 3 alt boyuttan oluşan bir yapıda uyum gösterdiği ve bu üç alt boyutun toplam varyansın \% 45'ini açıkladığı görülmüştür.Elde edilen sonuçlar 5 faktör kişilik modeli bağlamında analiz edilmiştir ve manevi aşkınlık boyutunun bağımsız bir bireysel farklılık grubu oluşturduğu tespit edilmiştir. Ölçeğin yapı geçerliliği çalışmasında uygulanan doğrulayıcı faktör analizi sonuçlarında $\mathrm{x}^{2} / \mathrm{df}=1.82, \mathrm{CFI}=.97, \mathrm{TLI}=.97, \mathrm{SRMR}=.07 \mathrm{RMSEA}=.07$ uyum indeksleri elde edilmiştir (Piedmont, 1999).

Elde edilen sonuçlara göre manevi aşkınlık ölçeğinin ibadet doyumu, evrensellik ve bağlantılılık olmak üzere üç boyuttan oluştuğu ortaya çıkmıştır. Güvenirlik çalışmasında Cronbach alpha katsayısı bağlantılılık alt boyutu için .64 , evrensellik için .83 ve ibadet doyumu için .87 bulunmuştur. Illk boyut olan ibadet doyumu, bireyin manevi aşkınlıkla karşı karşıya kalmasından kaynaklanan memnuniyet ve neşe hissini ifade eder (Ör: ibadetlerimden ve düşüncelerim vasıtasıyla manevi bir güç ve/veya huzur buluyorum).íkinci boyut evrensellik, yaşamın tek doğasına yönelik olan inancı ifade eder (Ör: daha yüksek bir boyutta hepimizin ortak bir bağı paylaştığını düşünüyorum). Üçüncü boyut bağlantılılık ise bireyin tüm insanlığın bir parçasının olduğuna olan inancını ifade eder (Ör: Hayatta benden sonra gelecek olanlar için endişeliyim). Yapılan araştırmalarda manevi aşkınlık ölçeğinin stres deneyimi ve sosyal destek gibi kavramların önemli bir yordayıcısı olduğu bulunmuştur (Piedmont, 1999).

\section{İşlem}

Manevi Aşkınlık Ölçeği'nin uyarlama çalışması için öncelikle ölçeği geliştiren Piedmont ile e-mail vasıtasıyla iletişime geçilmiştir. Devamında İngilizce ve Türkçe dillerine vakıf 6 uzman tarafından ölçek öncelikle Türkçeye çevrilmiştir. Elde edilen Türkçe form 2 uzman tarafından tekrar İngilizceye tercüme edilmiş ve iki form arasındaki tutarlılık incelenmiştir. Anlam ve dil bilgisi yönünden oluşan yeni formun orijinal formundan farklı olmadığı görülmüştür. Daha sonra rehberlik ve psikolojik danışmanlık bölümünde görev yapan 5 uzman ölçeği incelemiş ve ölçeğin uygulanabilir olduğu yönünde görüş belirtmiştir. Bunun sonrasında İngilizce ve Türkçe diline hakim felsefe, psikoloji ve İngiliz dili ve edebiyatı bölümlerinde öğrenim görmekte olan 42 üniversite öğrencisine önce İngilizce form 1 hafta sonra ise Türkçe form uygulanmıştır.

Katılımcılara araştırma ile ilgili gerekli bilgiler verildikten sonra ölçme araçları yüz yüze uygulanmıştır. Verilerin analizinde, dil geçerliği, ölçüt bağlantı geçerliği, iç tutarlık güvenirliği ve doğrulayıcı faktör analizi yöntemleri uygulanmıştır. Doğrulayıcı faktör analizi, gizil değişkenler ile ilgili kuramların test edilmesine dayanan ve ileri düzey araştırmalarda kullanılan bir tekniktir (Tabachnick ve Fidell, 2001). Doğrulayıcı faktör analizinde daha önceden belirlenen bir kuramsal yapı doğrultusunda geliştirilen ölçme aracından elde edilen verilere dayanarak, söz konusu yapının doğrulanıp doğrulanmadığı test edilmeye çalışılmaktadır (Maruyama, 1998). Ölçek uyarlama çalışmalarında açıklayıcı faktör analizi yerine orijinal araştırmadaki modelin hedef kültürde doğrulanıp doğrulanmadığını test etmek amacıyla doğrulayıcı faktör analizi yapılması gerekir (Seçer, 2015). Bu nedenle manevi aşkınlık ölçeğinin uyarlama çalışmasında doğrulayıcı faktör analizi tercih edilmiştir. Manevi Aşkınlık Ölçeği'nin kriter geçerliği kapsamında Manevi Yönelim Ölçeği ile ilişkisine bakılmıştır. Ölçeğin güvenirliği için iç tutarlık katsayıları hesaplanmıştır.

\section{YÖNTEM}

\section{Örneklem}

Bu araştırmada üç farklı çalışma grubundan veri toplanmıştır. Araştırmaya ilk olarak dil geçerliği çalışması için 2018-2019 akademik yılı güz döneminde eğitim dili İngilizce olan felsefe, psikoloji ve İngiliz dili ve edebiyatı bölümlerinde öğrenim görmekte olan 22 kadın, 20 erkek olmak üzere toplam 42 üniversite öğrencisi katılmıştır (\%52.4 kadın,\%47.6 Erkek). Ölçeğin yapı geçerliğini belirlemek için yapılan doğrulayıcı faktör analizi ve güvenirlik çalışması için Marmara Üniversitesi'nde öğrenim görmekte olan 217 kadın ve 207 erkek olmak üzere toplam 424 öğrenci katılmıştır ( \%51.2 kadın, \%48.8 Erkek). Ölçüt bağlantılı geçerlik çalışması için araştırmaya İstanbul Gelişim Üniversitesi Sağlık Bilimleri Meslek Yüksekokulu'nda öğrenim görmekte olan 38 kadın ve 30 erkek olmak üzere toplam 68 öğrenci katılmıştır (\% 55.9 kadın, \%44.1 Erkek).

\section{Veri Toplama Araçları}


Araştırma kapsamında katılımcılardan veri toplamak amacıyla Manevi Aşkınlık Ölçeği ve Manevi Aşkınlık Ölçeği'nin Türkçeye uyarlanması kapsamında ölçüt geçerliliğini test etmek amacıyla Manevi Yönelim Ölçeği kullanılmıştır. Kullanılan ölçekler ile ilgili detaylı bilgi aşağıda sunulmuştur.

\section{Manevi Aşkınlık Ölçeği}

Piedmont (1999) tarafından geliştirilen ölçek 24 maddeden oluşmaktadır. Ölçek evrensellik (yaşamın birliğine ve amacına olan inanç), ibadet doyumu (dua, tefekkür, meditasyon ve benzeri ibadetlerden kaynaklanan sevinç ve memnuniyet) ve bağlantılılık( kişisel sorumluluk duygusu ve tüm insanlıkla bağlantılı olma) olmak üzere üç alt boyuttan oluşur. 5'li likert tipi ölçekte maddeler 1 (kesinlikle katılmıyorum), 5 (kesinlikle katılmıyorum) şeklinde cevaplandırılmaktadır. Ölçeğin alt boyutları olan evrensellik, ibadet doyumu ve bağlantılıık için cronbach alfa güvenirlik katsayıları sırasıyla $.83, .87$ ve .64 'tür. Ölçekten elde edilen puanların refah, stres deneyimi ve psikolojik olgunluk gibi çeşitli psikolojik kavramları yordadığı görülmüştür.

\section{Manevi Yönelim Ölçeği}

Manevi Aşkınlık Ölçeği'nin Türkçeye uyarlanması sırasında ölçüt bağlantı geçerliliği kapsamında kullanılan Manevi Yönelim Ölçeği, bireyin manevi eğilimlerini ölçmek için Kasapoğlu (2015) tarafından geliştirilmiştir. 7'li likert tipi ölçek 16 maddeden oluşmaktadır. Yüksek puanlar bireyin manevi yöneliminin yüksek olduğunu ifade eder. Kasapoğlu (2015) tarafından belirtildiği üzere ölçeğin yapı geçerliliği çalışmasında açımlayıcı ve doğrulayıcı faktör analizi teknikleri kullanılmıştır. Açımlayıcı faktör analizi sonucunda ölçeğin tek boyutlu bir yapı gösterdiği saptanmıştır. Kasapoğlu'nun bulgularına göre ölçeğin toplam varyansın \%47.50'sini açıklayan bir faktörden oluştuğu ve tek boyut ile temsil edilen modelin uyum indekslerinin uygun olduğu belirtilmektedir $\left(\mathrm{x}^{2} / \mathrm{sd}_{2} 2.39\right.$, $\mathrm{RMSEA}=.06, \mathrm{SRMR}=.05, \mathrm{GFI}=.93, \mathrm{AGFI}=.90, \mathrm{CFI}=.95, \mathrm{IFI}=.95$, $\mathrm{NFI}=.92)$. Ayrıca, ölçeğin güvenirlik çalışması için yapılan birinci çalışmada .87, test-tekrar test güvenirlik katsayısı ise .84 olarak bulunduğu ifade edilmektedir.

\section{BULGULAR}

\section{Dil geçerliği}

İngilizce ve Türkçe dillerine hakim 42 kişinin İngilizce form puanları ile 7 gün sonra tekrar uygulanan Türkçe form toplam puanları arasındaki korelasyon katsayıları Tablo 1'de, madde korelasyon katsayıları Tablo 2'de ve ilişkili grup t-testi sonuçları ise Tablo 3'te verilmektedir.

Tablo1. Orijinal form ile Türkçe form arasındaki ilişkiye yönelik pearson momentler korelasyon analizi sonuçları

\begin{tabular}{lllll}
\hline Uygulama & $N$ & $\bar{X}$ & Ss & $r$ \\
\hline Türkçe form & 42 & 69.45 & 14.73 & $.94^{\star *}$ \\
İngilizce form & 42 & 68.90 & 14.75 & \\
\hline
\end{tabular}

${ }^{* *} p<.01$

Tablo 1'de görüldüğü üzere İngilizce form puanları ile Türkçe form puanları arasındaki korelasyon katsayısı $r=.94(p<.01)$ olarak bulunmuştur. Alt boyutlara göre ise İngilizce form ve Türkçe form arasındaki korelasyon katsayısı: ibadet doyumu alt boyutu için $r=.91$, evrensellik alt boyutu için $r=.91$ ve bağlantılılık alt boyutu için $r=85$ olarak bulunmuştur. Elde edilen sonuçlara göre ölçeğin Türkçe formunun, orijinal İngilizce formuna eşdeğer olduğu söylenebilir. 
Tablo. 2. Türkçe ve İngilizce Formlar Arasındaki Madde Korelasyon Katsayıları

\begin{tabular}{llll}
\hline Madde & $\mathrm{N}$ & $\mathrm{r}$ & $\mathrm{p}$ \\
\hline Tr 01 \&ing01 & 42 & .78 & .000 \\
Tr 02 \&ing 02 & 42 & .91 & .000 \\
Tr 03 \&ing 03 & 42 & .57 & .000 \\
Tr 04 \&ing 04 & 42 & .69 & .000 \\
Tr 05 \&ing 05 & 42 & .68 & .000 \\
$\operatorname{Tr} 06$ \&ing 06 & 42 & .88 & .000 \\
$\operatorname{Tr} 07$ \&ing 07 & 42 & .72 & .000 \\
$\operatorname{Tr} 08$ \&ing 08 & 42 & .87 & .000 \\
$\operatorname{Tr} 09$ \&ing 09 & 42 & .77 & .000 \\
$\operatorname{Tr} 10$ \&ing 10 & 42 & .65 & .000 \\
$\operatorname{Tr} 11$ \&ing 11 & 42 & .85 & .000 \\
$\operatorname{Tr} 12$ \&ing 12 & 42 & .84 & .000 \\
$\operatorname{Tr} 13$ \&ing 13 & 42 & .62 & .000 \\
$\operatorname{Tr} 14$ \&ing 14 & 42 & .88 & .000 \\
$\operatorname{Tr} 15$ \&ing 15 & 42 & .89 & .000 \\
$\operatorname{Tr} 16$ \&ing 16 & 42 & .83 & .000 \\
$\operatorname{Tr} 17$ \&ing 17 & 42 & .73 & .000 \\
$\operatorname{Tr} 18$ \&ing 18 & 42 & .63 & .000 \\
$\operatorname{Tr} 19$ \&ing 19 & 42 & .77 & .000 \\
$\operatorname{Tr} 20$ \&ing 20 & 42 & .68 & .000 \\
$\operatorname{Tr} 21$ \&ing 21 & 42 & .51 & .000 \\
$\operatorname{Tr} 22$ \&ing 22 & 42 & .81 & .000 \\
$\operatorname{Tr} 23$ \&ing 23 & 42 & .91 & .000 \\
$\operatorname{Tr} 24$ \&ing 24 & 42 & .73 & .000 \\
\hline & & &
\end{tabular}

Tablo 2'de görüldüğü üzere maddelerin tümü için İngilizce ve Türkçe formları arasındaki korelasyon katsayılarının yüksek düzeyde olduğu görülmektedir. 
Tablo 3.Dilsel Eşgeçerlik için ilişkili grup t-testi sonuçları

\begin{tabular}{|c|c|c|c|c|c|c|c|c|c|c|c|}
\hline & & $\bar{X}$ & SS & $\mathbf{t}$ & $\mathbf{p}$ & & & $\overline{\mathrm{X}}$ & SS & $\mathbf{t}$ & $\mathbf{p}$ \\
\hline \multirow[t]{2}{*}{1} & $\operatorname{Tr} 1$ & 2,54 & 1,36 & -.89 & .37 & 13 & $\operatorname{Tr} 13$ & 3,09 & 1,32 & .82 & .41 \\
\hline & İng1 & 2,66 & 1,26 & & & & İng 13 & 2,95 & 1,24 & & \\
\hline \multirow[t]{2}{*}{2} & $\operatorname{Tr} 2$ & 2,52 & 1,31 & -1.40 & .16 & 14 & $\operatorname{Tr} 14$ & 2,57 & 1,17 & .25 & .80 \\
\hline & İng 2 & 2,64 & 1,28 & & & & İng 14 & 2,54 & 1,29 & & \\
\hline \multirow[t]{2}{*}{3} & $\operatorname{Tr} 3$ & 3,42 & 1,21 & 1.47 & .14 & 15 & $\operatorname{Tr} 15$ & 2,64 & 1,44 & -1.43 & .16 \\
\hline & İng 3 & 3,16 & 1,28 & & & & İng 15 & 2,78 & 1,33 & & \\
\hline \multirow[t]{2}{*}{4} & $\operatorname{Tr} 4$ & 3,30 & 1,13 & .35 & .72 & 16 & $\operatorname{Tr} 16$ & 2,83 & 1,22 & .44 & .66 \\
\hline & İng 4 & 3,26 & 1,10 & & & & İng 16 & 2,78 & 1,17 & & \\
\hline \multirow[t]{2}{*}{5} & $\operatorname{Tr} 5$ & 3,57 & 1,17 & -.33 & .74 & 17 & $\operatorname{Tr} 17$ & 2,66 & 1,31 & -.81 & .41 \\
\hline & İng 5 & 3,61 & 1,16 & & & & İng 18 & 2,78 & 1,24 & & \\
\hline \multirow[t]{2}{*}{6} & $\operatorname{Tr} 6$ & 2,78 & 1,15 & -.27 & .78 & 18 & $\operatorname{Tr} 18$ & 2,28 & 1,21 & .61 & .54 \\
\hline & İng 6 & 2,80 & 1,19 & & & & İng 18 & 2,19 & 1,15 & & \\
\hline \multirow[t]{2}{*}{7} & $\operatorname{Tr} 7$ & 2,97 & 1,37 & -.75 & .45 & 19 & $\operatorname{Tr} 19$ & 2,42 & 1,29 & .18 & .85 \\
\hline & İng 7 & 3,09 & 1,35 & & & & İng 19 & 2,40 & 1,21 & & \\
\hline \multirow[t]{2}{*}{8} & $\operatorname{Tr} 8$ & 3,07 & 1,35 & -.46 & .64 & 20 & $\operatorname{Tr} 20$ & 2,76 & 1,33 & .74 & .46 \\
\hline & İng 8 & 3,11 & 1,29 & & & & İng 20 & 2,88 & 1,29 & & \\
\hline \multirow[t]{2}{*}{9} & $\operatorname{Tr} 9$ & 3,26 & 1,36 & -.48 & .62 & 21 & $\operatorname{Tr} 21$ & 2,57 & 2,57 & .28 & .78 \\
\hline & İng 9 & 3,33 & 1,44 & & & & İng 21 & 2,52 & 2,52 & & \\
\hline \multirow[t]{3}{*}{10} & $\operatorname{Tr} 10$ & 3,28 & 1,11 & -1.7 & .86 & 22 & $\operatorname{Tr} 22$ & 2,40 & 2,40 & -.68 & .49 \\
\hline & İng & 3,30 & 1,02 & & & & İng 22 & 2,47 & 2,47 & & \\
\hline & 10 & & & & & & & & & & \\
\hline \multirow[t]{3}{*}{11} & $\operatorname{Tr} 11$ & 2,90 & 1,16 & -1.0 & .32 & 23 & $\operatorname{Tr} 23$ & 3,45 & 3,45 & .33 & .74 \\
\hline & İng & 3,00 & 1,14 & & & & İng 23 & 3,42 & 3,42 & & \\
\hline & 11 & & & & & & & & & & \\
\hline \multirow[t]{3}{*}{12} & $\operatorname{Tr} 12$ & 2,71 & 1,33 & 1.48 & .14 & 24 & $\operatorname{Tr} 24$ & 3,21 & 3,21 & .92 & .35 \\
\hline & İng & 2,54 & 1,31 & & & & İng 24 & 3,09 & 3,09 & & \\
\hline & 12 & & & & & & & & & & \\
\hline
\end{tabular}

Tablo 3'te görüldüğü üzere Manevi Aşkınlık Ölçeği'nin Türkçe formunun, orijinal İngilizce formuna eşdeğer olduğu yapılan ilişkili grup t-testi sonuçlarına göre aralarında anlamlı bir fark olmadığı görülmüştür ( $p>$.05).Dilsel eş değerliğe ilişkin yapılan t- testi analizinde sorunlu bir madde olmadığı tespit edilmiştir. Bundan dolayı ölçeğin tüm maddelerinin dilsel eşdeğerliğe sahip olduğu söylenebilir. Tüm bu sonuçlara göre ölçeğin Türkçe formunun İngilizce formu ile eş değer olduğu sonucu tespit edilmiştir.

\section{Yapı Geçerliği}

Manevi Aşkınlık Ölçeği'nin Türkiye'deki üniversite öğrencilerinden oluşan örneklemde doğrulanıp doğrulanmadığını belirlemek için doğrulayıcı faktör analizi yöntemi kullanılmıştır. Elde edilen DFA sonucu ilk olarak ki kare değerinin serbestlik derecesine oranıyla değerlendirilmiştir. Ki kare değerinin serbestlik derecesine oranının 5'ten küçük olması gerekmektedir (Kline, 2005). Bu çalışmada bu oran (681.09/249) 2.73 olarak bulunmuştur. Modelin uyum iyiliği indekslerinde TLI, CFI, GFI ve IFI için kabul edilebilir uyum değerlerinin .90 ve üzeri olduğu, RMSEA ve SRMR için ise .08 ve daha düşük olması gerektiği belirtilmektedir (Tabachnick ve Fidell, 2001). Bu kriterler doğrultusunda modelin iyi uyum gösterdiği saptanmıştır. Ölçeğe ilişkin uyum indeksleri Tablo 4'te yol diyagramı ise Şekil-1'de, verilmiştir. 
Tablo 4.Manevi Aşkınlık Ölçeği'nin uyum iyiliği indekslerine ilişkin değerleri

\begin{tabular}{lcccccccc}
\hline Model & $x^{2}$ & $d f$ & TLI & RMSEA & SRMR & CFI & GFI & IFI \\
\hline Türkçe form & 681.09 & 249 & .92 & .06 & .05 & .93 & .97 & .95 \\
\hline
\end{tabular}

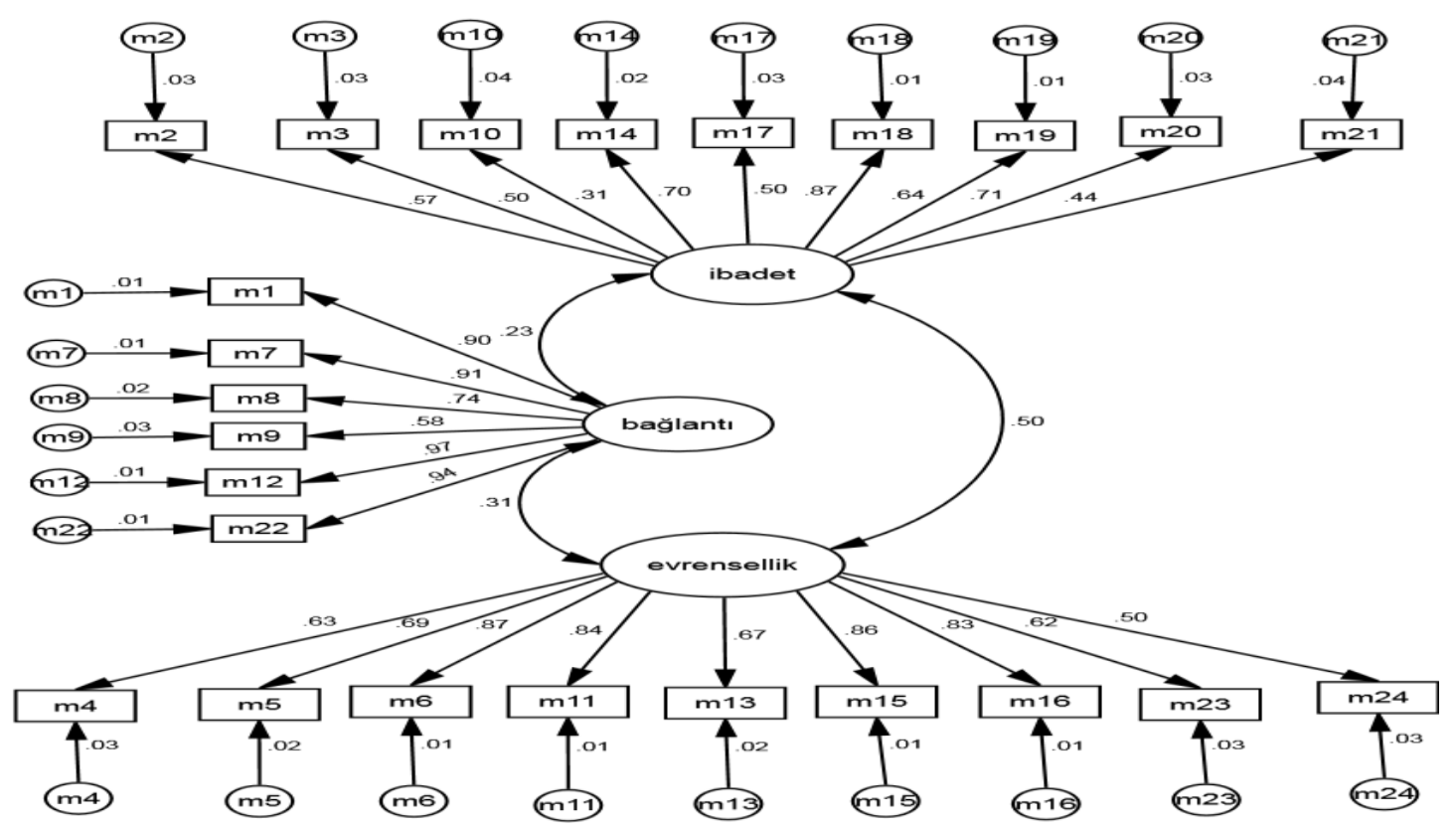

Şekil1.Manevi Aşkınlık Ölçeği'ne ilişkin ölçüm modeli ve faktör yükleri

Ölçeğin faktör yükleri yukarıda görüldüğü üzere .31 ile .97 arasında değişmektedir. Modelin uyum indeksleri incelendiğinde ölçeğin üç boyutlu modelinin kabul edilebilir düzeyde uyum verdiği görülmüştür $\left(x^{2}=681,09, \mathrm{df}=249, \mathrm{p}<.001 ; \mathrm{GFI}=.97 ; \mathrm{IFI}=.95 ; \mathrm{CFI}=.93 ; \mathrm{TLI}=.92 ; \mathrm{SRMR}=.05 ; \mathrm{RMSEA}=.06\right)$.

\section{Ölçüt Bağlantı Geçerlik}

Manevi Aşkınlık Ölçeğinin ölçüt bağlantı geçerliliği için Manevi Yönelim Ölçeği ile arasındaki ilişkiye bakılmıştır. Ölçekler ve alt boyutlar arasındaki korelasyon katsayılarını ve betimsel istatistiklerini gösteren bulgular Tablo 3'te yer almaktadır.

Tablo5.Manevi aşkınlık ile manevi yönelim arasındaki ilişkilere yönelik korelasyon katsayıları

Tablo 3'te görüldüğü üzere Manevi Aşkınlık Ölçeği'nin toplam puanı ile Manevi Yönelim Ölçeği'nin toplam puanı arasında (.66) pozitif ilişki bulunmuştur. Manevi yönelim ölçeği ile manevi aşkınlık ölçeğinin alt boyutları ibadet doyumu (.79), evrensellik (.38) ve bağlantılılık (.36) arasında pozitif ilişki bulunmuştur. Elde edilen değerler Manevi Aşkınlık Ölçeği'nin geçerliliğine kanıt olarak değerlendirilebilir. 


\section{Güvenirlik Çalışması}

Manevi Aşkınlık Ölçeğinin tümü için Cronbach alpha iç tutarlıık güvenirlik katsayısı.90 olarak bulunmuştur. Alt boyutlar için iç tutarlık güvenilirlik katsayısı hesaplandığında ise ibadet doyumu için .84, evrensellik için .91 , bağlantılılık için .93bulunmuştur.

\section{TARTIŞMA, SONUÇ VE ÖNERILER}

Bu çalışma Piedmont (1999) tarafından geliştirilen ve manevi aşkınlığı üç alt boyutla ölçen manevi aşkınlık ölçeğini Türkçeye uyarlamak amacıyla gerçekleştirilmiştir. Bu amaçla öncelikle ölçeğin orijinal formu İngilizce ve Türkçe dil alan uzmanı 6 kişi tarafından Türkçeye çevrilmiştir. Daha sonra iki bağımsız uzman ölçeği İngilizceye geri çevirmiştir. Son düzenlemelerin devamında Türkçe form uygulamaya hazır hale getirilmiştir.

Manevi aşkınlık ölçeği için yapılan geçerlik sonuçları ölçeğin geçerli bir ölçme aracı olduğunu göstermektedir. Yapılan doğrulayıcı faktör analizi orijinal formunda yer alan 3 alt boyutunun doğrulandığı görülmektedir. Yapılan doğrulayıcı faktör analizi sonucunda elde edilen korelasyon değerleri. 31 ile. 97 arasında değişkenlik göstermektedir. .30 ve üzerinde değer alan maddelerin temsil gücünün yeterli olduğu belirtilmektedir (Büyüköztürk, 2018). Bu sebeple herhangi bir madde ölçeğin orijinal versiyonunun Türkçeye uyarlanması sonucunda çıkarılmamıştır. Ölçeğin uyum indeksi değerlerinin kabul edilebilir değerlerde olduğu ve 3 boyutlu yapının bu çalışma grubunda geçerli olduğu bulunmuştur. Elde edilen sonuçlar manevi aşkınlık ölçeğinin geçerli bir ölçme aracı olduğuna kanıt olarak gösterilebilir.

Ölçeğin güvenirlik çalışmalarında Cronbach alpha iç tutarlık katsayısı ölçeğin tümü için 90 olarak bulunmuştur. Alt boyutlar için ise ibadet doyumu için .84, evrensellik için .91, bağlantılılık için .93 bulunmuştur. Cronbach alpha iç tutarlık katsayısı ise kabul edilebilir değer olarak Özgüven (1994) .70 ve üzeri bir değer olması gerektiğini ifade etmektedir. Elde ettiğimiz bulgulara göre ölçeğin tüm puanı ve alt boyutlarının yeterli derecede güvenilir olduğunu belirtebiliriz.

Manevi Aşkınlık Ölçeği'nin ölçüt geçerliliği çalışmasında Manevi Yönelim Ölçeği ile arasındaki ilişki incelenmiştir. Ölçeğin Hindistan kültürüne uyum çalışmalarında geçerliliği için yaşam amacı, beş faktör kişilik testi ve inanç olgunluğu ölçekleri kullanılmıştır. Elde edilen sonuçlarda manevi aşkınlık ölçeğinin yaşam amacı ve inanç olgunluğu ölçeğinin olumlu alt boyutları ile pozitif ilişkili olduğu görülmüştür. Ayrıca beş faktör kişilik testinin dışa dönüklük, açıklık, uyumluluk ve öz disiplin boyutları ile pozitif, nevrotiklik boyutu ile ise negatif ilişki içerisinde olduğu bulunmuştur (Piedmont ve Leach, 2002). Yapılan çalışmada manevi yönelim ölçeği ile elde edilen pozitif ilişki kuramsal çerçeve ve daha önceki çalışmalarla uygun olduğunu göstermiştir.

Manevi aşkınlık ölçeğinin geliştirme çalışmaları (Piedmont, 1999) devamında Hindistan (Piedmont ve Leach,2002) ve Filipinler (Piedmont,2007)'de yapılan uyarlama çalışmaları ölçeğin farklı kültürlerde geçerli ve güvenilir bir ölçme aracı olduğunu desteklemiştir. Yapılan bu çalışma ile ölçeğin Türkiye'de de psikometrik açıdan geçerli ve güvenilir sonuçlar görüldüğünden bu durum maneviyatın evrenselliği şeklinde ifade edilebilir.

Yapılan çalışmanın ülkemizdeki psikolojik danışmanlık alanındaki özellikle maneviyatla ilgili akademik ve uygulama alanındaki çalışmalara destek sağlaması düşünülmektedir. Dünya üzerinde özellikle 21. yüzyılda maneviyat alanında birçok bilimsel araştırmalar yapılmaktadır. Maneviyatın psikoterapideki rolü son zamanlarda ilgi görmektedir. Artan ilgiyle maneviyatın psikolojik danışmanlık sürecinde kullanılmasının bazı danışanlar için faydalı olduğu görülmektedir (Post ve Wade, 2009). Örtük veya açık bir şekilde maneviyat ve ilgili kavramlar psikolojik danışma sürecinin içine girer. Ancak danışman veya terapist bu duruma hazırlıksız olması sebebiyle bu boyutun farkında olamayabilir. Maneviyatı müzikte, yanımızdan geçen bir yabancının gülümsemesinde, alaca karanlıkta gökyüzünün renginde veya uyandığımız güne şükür ederken bulabiliriz. Zıt bir şekilde maneviyatı kayıp ve boşluk duygularını hissederken, hayatın anlam ve amacını sorgularken, terk edilme hissine kapıldığımızda veya haksızlık karşısında ağlarken de hissedebiliriz (Pargament, 2007). Aslında maneviyat ve ilgili kavramlar çoğu zaman danışan ve danışman ilişkisinde çözümün bir parçası olabilmektedir (İme, 2019). Ülkemizde de özellikle psikoloji ve psikolojik danışmanlık gibi ruh sağlığını ilgilendiren alanlarda hizmet veren uzmanların danışanın bu boyutunun farkında olmasının önemli olabileceği düşünülmektedir. Krageloh, Chai, Shepherd ve Billington (2010) maneviyatın ve ilgili kavramların 
bireylerin yaşamış olduğu stres gibi olumsuz durumlarda bir baş etme metodu olarak kullanılabileceğini ifade eder.

Yapılan bazı araştırmalar üniversite öğrencilerinde manevi aşkınlık ile affedicilik ve alçak gönüllülük gibi pozitif psikoloji alanında yeni araştırılan kavramlarla pozitif ilişkili olduğunu göstermektedir (Powers, Nam, Rowatt ve Hill, 2007). Bu bağlamda ülkemizde de üniversite öğrencilerinde veya diğer yetişkin gruplarda manevi aşkınlığın affedicilik, iyi oluş, duygusal zeka, öz anlayış gibi kavramlarla ilişkilerini araştıracak çeşitli araştırmalar yapılabilir. Yine özellikle psikolojik danışma alanında son yıllarda oldukça araştırılan yardım etme, sorumluluk üstlenme ve bağışta bulunma gibi birçok olumlu sosyal davranışı içeren özgecilik (Ümmet, Ekşi ve Otrar, 2013) gibi kavramlarla da manevi aşkınlık arasındaki ilişkilere bakılabilir. Yapılacak olan çalışmalarda kullanılabilecek olan bu ölçeğin önemli bir ihtiyacı giderebileceği düşünülmektedir.

Araştırmanın en önemli sınırlıı̆̆ını çalışma grubunun tamamen üniversite öğrencilerinden oluşması oluşturmaktadır. Ölçeğin bundan sonra yapılacak çalışmalarda farklı eğitim ve yaş gruplarında psikometrik özelliklerinin incelenmesi faydalı olabilir. Bu sınırlılığa rağmen, manevi aşkınlık ölçeğinin Türkçe formunun yapılacak olan bilimsel çalışmalarda bireylerin manevi aşkınlık düzeylerini belirlemede geçerli ve güvenilir bir ölçek olduğu söylenebilir. Illeride yapılacak olan çalışmalarda Manevi Aşkınlık Ölçeği'nin şükran, umut, iyi oluş, yaşam doyumu gibi pozitif yapılarla ve depresyon, kaygı gibi negatif yapılarla ilişkileri üzerinde durulabilir.

\section{KAYNAKÇA/REFERENCES}

Bray, P.(2011). Naming spirituality in counselor education. New Zealand Journal of Counseling, 76-97.

Büyüköztürk, Ş.(2018).Sosyal Bilimler için veri analizi el kitabı. istatistik araştırma deseni. SPSS uygulamaları ve yorum (24.Baskı). Ankara:Pegem Akademi.

Çokluk, Ö., Şekercioğlu, G. ve Büyüköztürk, Ş.(2010). Sosyal bilimler için çok değişkenli istatistik: SPSS ve Lisrel uygulamaları. Ankara: Pegem Akademi.

Delaney, C. (2005).The spirituality scale: development and psychometric testing of a holistic instrument to assess the human spiritual dimension. Journal of Holistic Nursing, 23(2), 145-167.

Doyle, D. (1992).Have we looked beyond the physical and psychosocial? Journal of Pain and Symptom Management, 7,302-311.

Ekşi, H. Takmaz, Z., ve Kardaş, S. (2016). Spirituality in psychotherapy settings: A phenomenological inquiry into the experiences of Turkish health professionals. Spiritual Psychology and Counseling, 1, 89108.

Ekşi, H., Okan, N. ve Mert, H.Ş.(2018). Kişisel anlam profili ölçeği kısa formunun geçerlik ve güvenirlik çalışması. Marmara Üniversitesi Atatürk Eğitim Fakültesi Eğitim Bilimleri Dergisi,47(47), 157-168.

Hill, P. C.,Pargament, K. I., Hood, R. W., McCullough, M. E., Swyers, J. P., Larson, D. B., and Zinnbauer, B. J. (2000). Conceptualizing religion and spirituality: points of commonality, points of departure. Journal for the Theory of Social Behavior, 30, 51-77.

İme, Y.(2019). Solution focused brief therapy and spirituality. Spiritual Psychology and Counseling, 4(2), 143161

Kasapoğlu, F.(2015).Manevi yönelim ölçeğinin geliştirilmesi: geçerlik ve güvenirlik çalışması. inönü Üniversitesi Eğitim Fakültesi Dergisi, 16(3),51-68

Kline, R.B.(2005).Principles and practice of structural equation modeling (Second Edition).NY: Guilford Publications.

Krageloh,C.U., Chai, P.P.M., Shepherd,D., and Billington,R. (2010). How religious coping is used relative to other coping strategies depends on the individual's level of religiosity and spirituality. Journal of Religion and Health, 51(4), 1137-1151

Maruyama, G.M.(1998).Basics of structural equation modeling (First Edition).CA:Sage Publications.

Oxford Dictionary. (2017). Oxford: Oxford University Press. 
Pargament, I.K.(2007).Spirituality Integrated Psychotherapy. Understanding and Adressing the Sacred. NY: The Guilford Press.

Piedmont, R.L. (1999). Does spirituality represent the sixth factor of personality? Spiritual transcendence and the five-factor model. Journal of Personality, 67,985-1013.

Piedmont, R.L. (2001).Spiritual transcendence and the scientific study of spirituality. Journal of Rehabilitation, 67, 4-14.

Piedmont,R.L.(2007). Cross-cultural generalizability of the spiritual transcendence scale to the Philippines: Spirituality as a human universal. Mental Health, Religion and Culture, 10(2), 89-107.

Piedmont,R.L. and Leach, (2012).Cross-cultural generalizability of the spiritual transcendence scale in India: spirituality as a human universal. American Behavioral Scientist,45(12),1888-1901.

Post,B.C., and, Wade,N.G.(2009). Religion and spirituality in psychotherapy: a practice-friendly review of research. Journal of Clinical Psychology, 65(2), 131-146

Powers, C.,Nam, R.K., Rowatt, W.C. andHill, P.C.(2007). Associations between humility, spititual transcendence, and forgiveness. Research in the Social Scientific Study of Religion, 18, 75-94.

Seidlitz,L.,Abernethy,A.D., Duberstein,P.R., Evinger,J.S., Chang,T.H., and Lewis, B.L.(2002). Development of the spiritual transcendence index. Journal for The Scientific Study of Religion,41(3),439-453

Shafranske,E.P., and Gorsuch, R.L.(1984).Factors associated with the perception of spirituality in psychotherapy. Journal of Transpersonal Psychology, 16, 231-241.

Seçer, i..(2015). Psikolojik test geliştirme ve uyarlama süreci (1.Baskı).Ankara: Anı Yayıncılık

Sümer, N.(2000). Yapısal eşitlik modelleri. Türk Psikoloji Yazıları,3(6),49-74.

Özgüven, E.(1994). Psikolojik testler. Ankara: Yeni Doğuş Matbaası.

Şirin, T.(2018). Maneviyat ölçeğinin geliştirilmesi: geçerlik ve güvenirlik çalışması. Turkish Studies Social Sciences, 13(18), 1283-1309.

Tabachnick B.G. and Fidel, L.S.(2001).Using multivariate statistics (4 ${ }^{\text {th }}$ Edition).MA: Allyn and Bacon

Ümmet,D., Ekşi,H. ve Otrar,M. (2013). Özgecilik (alturism) ölçeği geliştirme çalışması. Değerler Eğitimi Dergisi, 11(26), 301-321

Zinnbauer, J.B. and Pargament,K.I. (2005). Religiousness and spirituality. In R.F.Paloutzian and C.L.Park (Eds.), Handbook of the psychology of religion and spirituality (p.21-42). New York: The Guilford Press.

Iletișim/Correspondence

Uzman Psikolojik Danışman Yakup IME

imeyakup@gmail.com

Prof.Dr.Halil EKȘi

h.eksi70@gmail.com

Doç.Dr.Füsun EKŞi

füsun.eksi@medeniyet.edu.tr 